\title{
Hepatitis E virus outbreak associated with rainfall in the Central African Republic in 2008-2009
}

\author{
Vianney Tricou1*, Julie Bouscaillou², Gina-Laure Laghoe-Nguembe ${ }^{3}$, Aubin Béré ${ }^{4}$, Xavier Konamna', \\ Benjamin Sélékon ${ }^{1}$, Emmanuel Nakouné ${ }^{1}$, Mirdad Kazanji ${ }^{5}$ and Narcisse P. Komas ${ }^{3}$
}

\begin{abstract}
Background: Infection by hepatitis E virus (HEV) can cause a high burden of morbidity and mortality in countries with poor access to clean water and sanitation. Our study aimed to investigate the situation of HEV infections in the Central African Republic (CAR).

Methods: A retrospective analysis of the blood samples and notification forms collected through the national yellow fever (YF) surveillance program, but for which a diagnosis of YF was discarded, was carried out using an antiHEV IgM ELISA and a HEV-specific RT-PCR.

Results: Of 2883 YF-negative samples collected between January 2008 and December 2012, 745 ( 26\%) tested positive by at least either of the 2 tests used to confirm HEV cases. The results revealed that the CAR was hit by a large HEV outbreak in 2008 and 2009. The results also showed a clear seasonal pattern with correlation between HEV incidence and rainfall in Bangui. A phylogenetic analysis showed that the circulating strains belonged to genotypes $1 \mathrm{e}$ and $2 \mathrm{~b}$.

Conclusions: Overall, this study provides further evidences that HEV can be a significant cause of acute febrile jaundice, particularly among adults during rainy season or flood, in a country from Sub-Saharan Africa.
\end{abstract}

Keywords: Hepatitis E virus, Waterborne disease, Preventable disease, Epidemiology, Central Africa

\section{Background}

Hepatitis E virus (HEV) infection represents a significant public health problem in many parts of the world, particularly in Africa where it can cause outbreaks of acute hepatitis in areas with a high population density, heavy seasonal rainfall and high evapotranspiration rates [1,2]. HEV has two epidemiological profiles in humans. HEV genotypes 3 and 4 typically cause sporadic cases in developed countries through zoonotic or foodborne transmission. In developing countries, HEV genotypes 1 and

\footnotetext{
*Correspondence: vianney.tricou@gmail.com

'Laboratoire des Arbovirus, Institut Pasteur de Bangui, Bangui, Central African Republic BP 923

Full list of author information is available at the end of the article
}

2 are responsible for large waterborne outbreaks, which primarily occur among young adults during the rainy season. Symptomatic HEV infection consists in a short prodromal phase with asthenia, fever, abdominal pain, vomiting and anorexia that appears about 3 to 8 weeks after inoculation, followed by the appearance of jaundice [3]. While the disease is usually self-limited, outbreaks result in high attack rates in young adults and fatality rate among pregnant women can be up to $20 \%$ during the third trimester of pregnancy $[4,5]$. While a marketed vaccine is available, the World Health Organization (WHO) does not recommend its routine use because of insufficient safety and efficacy data [6].

C C The Author(s). 2020 Open Access This article is licensed under a Creative Commons Attribution 4.0 International License, which permits use, sharing, adaptation, distribution and reproduction in any medium or format, as long as you give appropriate credit to the original author(s) and the source, provide a link to the Creative Commons licence, and indicate if changes were made. The images or other third party material in this article are included in the article's Creative Commons licence, unless indicated otherwise in a credit line to the material. If material is not included in the article's Creative Commons licence and your intended use is not permitted by statutory regulation or exceeds the permitted use, you will need to obtain permission directly from the copyright holder. To view a copy of this licence, visit http://creativecommons.org/licenses/by/4.0/ The Creative Commons Public Domain Dedication waiver (http://creativecommons.org/publicdomain/zero/1.0/) applies to the data made available in this article, unless otherwise stated in a credit line to the data. 
The Central African Republic (CAR) is among the poorest countries in the world. The CAR lacks basic infrastructures and access to essential sanitation, and it has endured decades of recurring violence and destructions. In 2015, the CAR ranked last in terms of Human Development Index [7]. HEV is endemic in the CAR with a reported seroprevalence up to $24 \%$ in young adults and regular outbreaks documented [8-11]. HEV infection represents an important differential diagnosis of yellow fever (YF) which is also endemic in the CAR and is closely monitored through a national program of surveillance. The aim of our work was to provide new insights into the HEV epidemiology and circulating strains in the CAR by using the data and samples collected between 2008 to 2012 through the YF surveillance.

\section{Methods}

\section{Sample and data collection}

We used longitudinal surveillance data from the national network of healthcare facilities, through which all suspected cases of YF were systematically captured. As recommended by the WHO, YF is suspected in case of acute onset of fever followed within 2 weeks by jaundice [12]. In case of suspected YF, healthcare facilities throughout the country, regardless of their level or sector, are asked to collect a blood sample, to fill out a standardized notification form (with date of jaundice onset, age, gender and province of residence), to place the sample in a cooler and to ship it immediately to the Institut Pasteur in Bangui (CAR's capital and main city) for laboratory confirmation. All sera are then rapidly tested for the presence of IgM antibodies against YF virus by an IgM capture ELISA [13].

\section{Sample testing}

Plasma samples collected between January 2008 and December 2012 through the YF surveillance and found negative for anti-YF IgM were retrospectively tested by HEV IgM ELISA Dia.Pro kit reference EVM.CE (Diagnostic Bioprobes srl, Milan, Italy) [14, 15] and/or by real-time RT-PCR, as previously described [16]. For the RT-PCR testing, viral RNA was extracted using QIAamp Viral RNA Mini Kit (QIAGEN, Courtaboeuf, France), and then retrotranscribed into cDNA using the High Capacity cDNA Reverse Transcription Kit (Applied Biosystems, Foster City, CA, USA). A HEV case was confirmed if the sample was positive for IgM antibodies and/or for viral RNA amplification.

\section{Phylogenetic analysis}

A nested RT-PCR amplifying a 348-bp portion of the open reading frame 2 region was performed as previously described [17] on RNA samples selected amongst the samples that tested positive with the real-time RT-
PCR. The amplicons were purified using QIAquick PCR Purification Kit (50), (QIAGEN, Hilden, Germany) and then sent to GATC Biotech (Konstanz, Germany) for direct sequencing. Phylogenetic analysis of the obtained sequences was performed using reference strains for different HEV genotypes and subtypes [18]. A maximumlikelihood tree was constructed using PhyML version 3.1 with 100 bootstrap replications and automatic substitution model selection by SMS $[19,20]$.

\section{Statistical analyses}

Chi-square and Wilcoxon-Mann-Whitney tests were used to compare characteristics of HEV cases versus cases of other etiologies. Temporal and geographical distributions of HEV cases were descriptively analyzed. Incidence (provided as a rate per 100,000 persons per year) was calculated for each district using district population according to the last national census from 2003 [21]. Monthly occurrence of HEV cases in Bangui was compared with rainfall data from the Meteorology Unit of Bangui International Airport. Temporal correlations were examined statistically by computing the Pearson correlation coefficient. Year period from May to October was considered as the rainy season. Statistical analyses were performed using STATA 11.0.

\section{Results \\ HEV testing results}

Between January 2008 and December 2012, 3236 samples were collected and tested for YF-specific IgM at the Institut Pasteur in Bangui [13]. Of 3181 YF-negative samples, 2883 were tested for HEV-specific IgM and/or viral RNA (1402 [48.6\%] were tested for both, 1409 for HEV IgM only [48.9\%], and 72 [2.5\%] for HEV RNA only), 298 had insufficient volume (Fig. 1). Of note, the proportion of samples that could be tested was different according to the year, ranging from $80.7 \%$ in 2008 to 97.7\% in 2012 (Additional Table 1). Overall, 635 samples tested positive for HEV IgM (22.6\% of the 2811 samples tested by ELISA), and 308 samples tested positive for HEV RNA $(20.9 \%$ of the 1474 samples tested by realtime RT-PCR). When considering positivity for HEV IgM and/or viral RNA, 745 (25.8\% of the 2883 samples tested by at least one test) were positive for HEV (Fig. $1)$.

\section{Characteristics of HEV cases}

Among HEV cases, $44.0 \%$ were women, and the median age was 23 years. Compared to jaundice cases of other etiology, HEV cases were significantly associated with older age, urban setting and rainy season (Table 1). The proportion of HEV cases among jaundice cases varied significantly with age, ranging from $\sim 14 \%$ in cases $\leq 5$ 


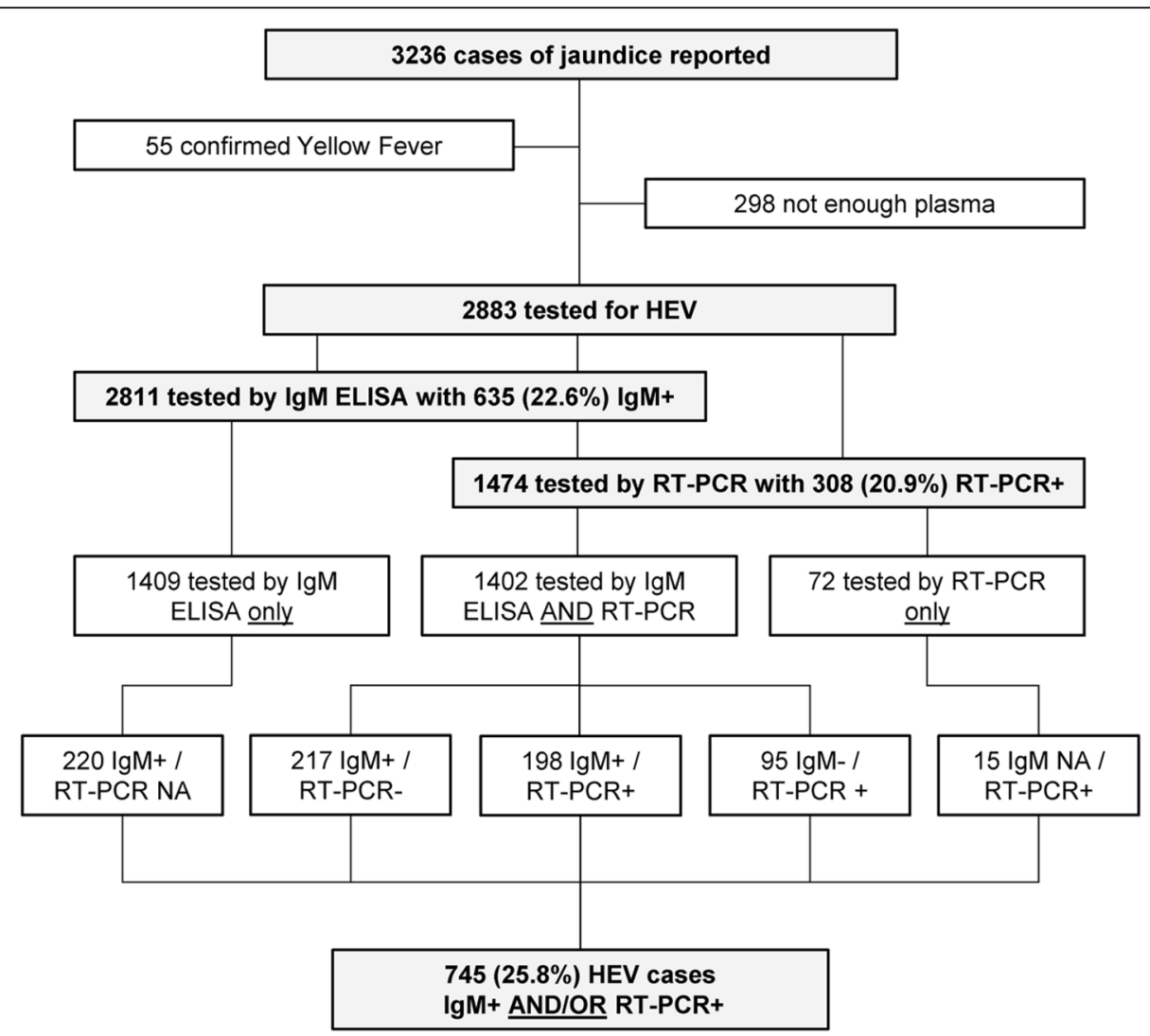

Fig. 1 Flow chart of the HEV testing. NA: not available

Table 1 Characteristics of the HEV cases compared to cases of other etiologies

\begin{tabular}{|c|c|c|c|c|c|c|c|}
\hline & \multicolumn{2}{|l|}{ Total } & \multicolumn{2}{|l|}{ HEV cases } & \multicolumn{2}{|c|}{ Cases of other etiologies } & \multirow[t]{2}{*}{$p$} \\
\hline & $N=2883$ & & $N=745$ & & $N=2138$ & & \\
\hline \multicolumn{8}{|l|}{ Sex $n, \%$} \\
\hline Female & 1239 & $43.0 \%$ & 327 & $44.0 \%$ & 912 & $42.7 \%$ & 0.445 \\
\hline Male & 1642 & $57.0 \%$ & 417 & $56.0 \%$ & 1225 & $57.3 \%$ & \\
\hline Age (median, IQR) & \multicolumn{2}{|l|}{$21,11-30$} & \multicolumn{2}{|l|}{$23,17-33$} & \multicolumn{2}{|l|}{$20,8-30$} & $<0.001$ \\
\hline \multicolumn{8}{|l|}{ Year n, \% } \\
\hline 2008 & 501 & $17.4 \%$ & 270 & $36.3 \%$ & 231 & $10.8 \%$ & \multirow[t]{5}{*}{$<0.001$} \\
\hline 2009 & 813 & $28.2 \%$ & 352 & $47.3 \%$ & 461 & $21.6 \%$ & \\
\hline 2010 & 615 & $21.3 \%$ & 83 & $11.2 \%$ & 532 & $24.9 \%$ & \\
\hline 2011 & 438 & $15.2 \%$ & 25 & $3.4 \%$ & 413 & $19.3 \%$ & \\
\hline 2012 & 516 & $17.9 \%$ & 15 & $2.0 \%$ & 501 & $23.4 \%$ & \\
\hline \multicolumn{8}{|l|}{ Season n, \% } \\
\hline Dry & 1257 & $43.6 \%$ & 254 & $34.1 \%$ & 1003 & $46.9 \%$ & \multirow[t]{2}{*}{$<0.001$} \\
\hline Rainy & 1626 & $56.4 \%$ & 491 & $65.9 \%$ & 1135 & $53.1 \%$ & \\
\hline \multicolumn{8}{|l|}{ Location n, \% } \\
\hline Bangui & 1037 & $36.1 \%$ & 356 & $47.8 \%$ & 681 & $31.9 \%$ & \multirow[t]{2}{*}{$<0.001$} \\
\hline Rest of the country & 1839 & $63.9 \%$ & 388 & $52.2 \%$ & 1451 & $68.1 \%$ & \\
\hline
\end{tabular}


years of age to $\sim 30 \%$ in cases $>15$ years old $(p<0.001)$ (Additional Table 2).

\section{Temporal and geographical distribution of HEV cases}

The monthly number of HEV cases showed a seasonal pattern, with an average peak incidence between June and September (Fig. 2). Geographical distribution by year highlighted a major epidemic situation across the whole country in 2008-2009 with up to 27 reported cases per 100,000 person-years in Bangui in 2009. In addition, the monthly number of HEV cases in Bangui was strongly correlated with considerable precipitation during the 2008 and 2009 rainy seasons (rho spearman 0.563, $p<0.001$ ) (Fig. 2).

\section{Phylogenetic analysis}

Ninety-six RNA samples were analyzed by the nested RT-PCR with 24 high quality sequences obtained (GenBank accession numbers from KF734739 to KF734762). Phylogenetic analysis of these sequences showed closely related viruses belonging to genotype 1 subtype e in 23 samples ( 93-100\% of nucleotide sequence identity) (Fig. 3). These viruses are closely related to strains from other sub-Saharan African countries with up to $\sim 95 \%$ of nucleotide sequence identity (Fig. 3) [22]. The phylogenetic analysis also showed one strain that belongs to genotype 2 subtype b that is closely related ( $\sim 90-93 \%$ of identity) to strains isolated from an outbreak in Nigeria in 2017 [23], in France from a person with history of recent travel to Senegal [24], and during a recent outbreak in Burkina Faso (Fig. 3) [25]. Of note, this strain is highly related to the strain isolated in 2008 in the CAR (100\% of identity) [11].

\section{Discussion}

We report here the use of a vast collection of samples and related notification forms that represented a unique opportunity to investigate the epidemiology of HEV infection in the CAR. These country-level five-year results confirm that HEV can be a significant cause of acute febrile jaundice in the CAR, particularly in adults during the rainy season or following flood. Therefore, a diagnosis of HEV should be considered in case of clustered febrile jaundice cases, i.e. $\geq 5$ cases sharing the same water supply [26]. The addition to the notification form used by the YF surveillance of a question about the water supply of the icteric case should also be considered. This could contribute to the early identification of contaminated water supplies and the rapid implementation of corrective actions. Given the current situation in the CAR with recurrent population displacements and destruction, our data also strongly supports the implementation of preventive actions like the development of outbreak response plans for high-risk areas (camp of refugees and internally-displaced people) that include elements about early diagnosis.

These results showed a large outbreak across the CAR in 2008-2009 particularly in Bangui, which is the capital city and main urban center of the country (Bangui concentrates about $1 / 5$ of the country population). Overall, there was about a quarter of the febrile jaundice cases

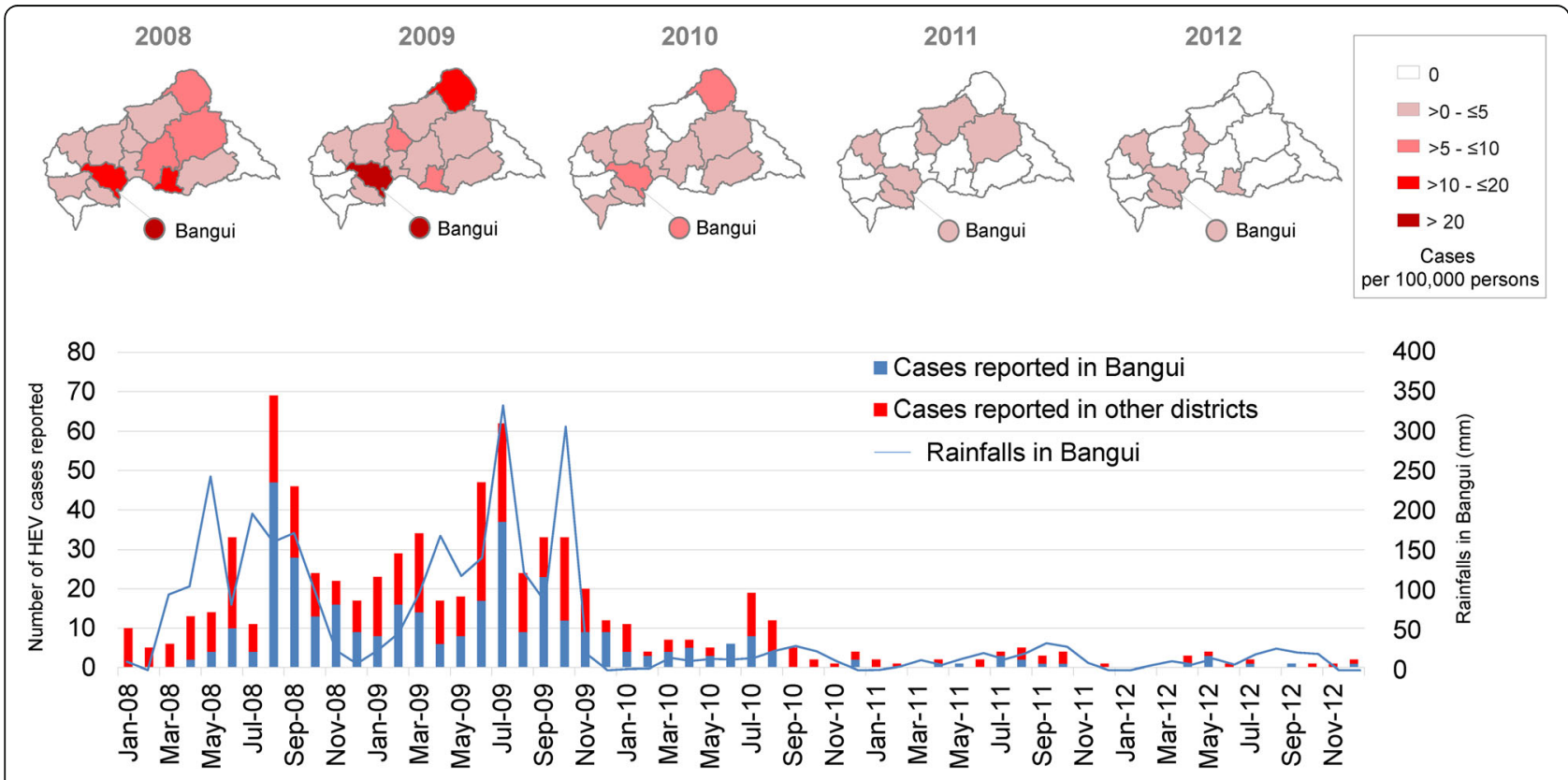

Fig. 2 Temporal and geographical distribution of HEV cases in the CAR with the monthly rainfall in Bangui - 2008-2012 


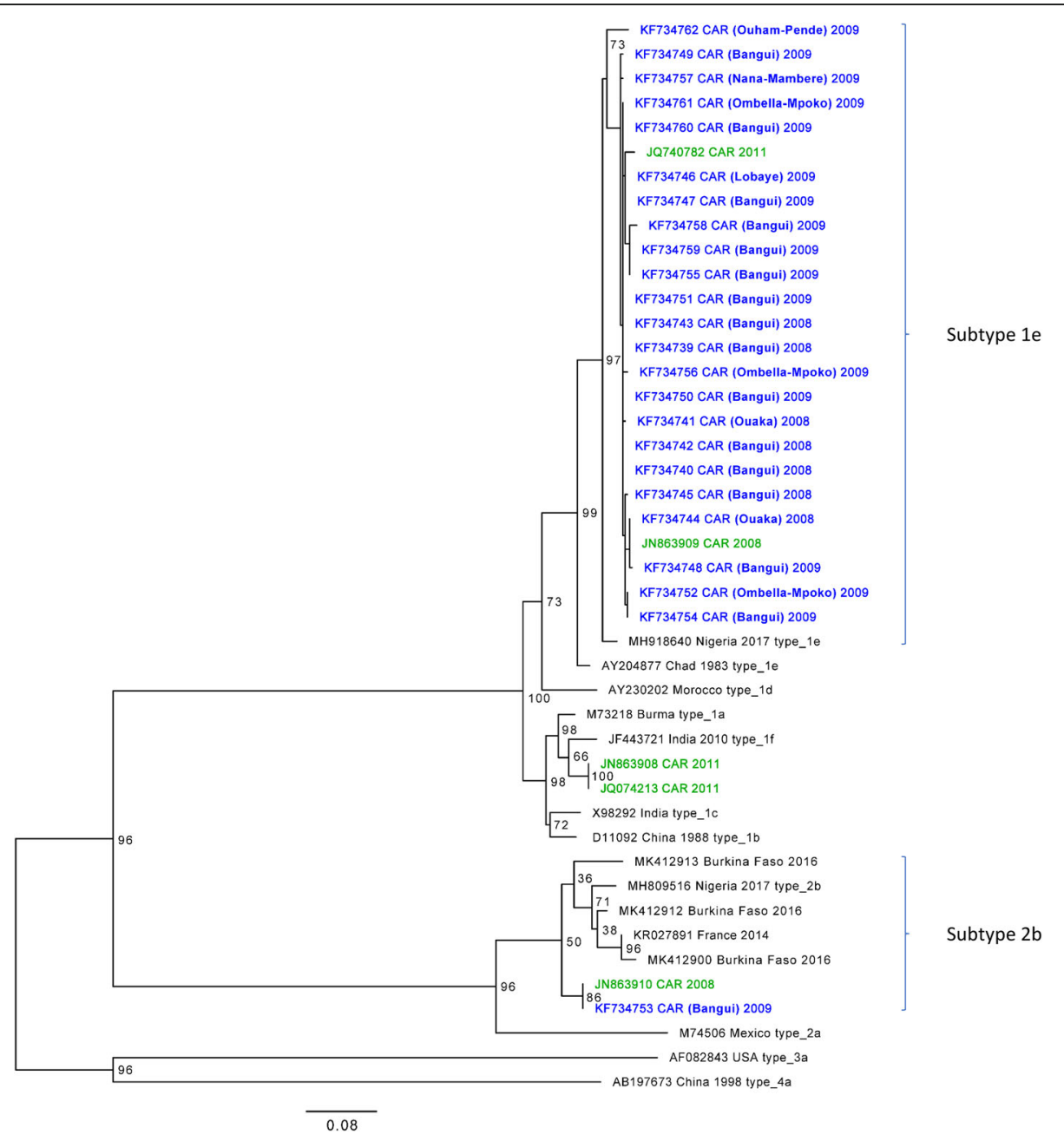

Fig. 3 Phylogenetic analysis of HEV strains from the CAR - 2008-2012. Scale bar represents nucleotide substitutions per site. Percentages of replicate trees in which the associated virus isolates clustered together in the bootstrap test (100 replicates) are shown next to the branches. The sequences generated in this study are depicted in blue. The sequences generated in Bouscaillou et al. 2013 [11] are depicted in green. These sequences are also from samples collected in the CAR during the period 2008-2012

collected through the YF surveillance being tested positive for HEV. Differences in seroprevalence between rural and urban areas have been reported. In Gabon, one study found a higher prevalence in urban compared with rural areas, while another study in South Africa found a higher HEV seroprevalence in rural compared with urban areas $[27,28]$. In our study (which was not a seroprevalence study), a higher incidence (34\% versus $21 \%$ of the febrile jaundice cases) was found in Bangui compared to the rest of the country. This might be due to the higher population density in Bangui with water supplies that are shared by a lot of people [2]. However, the incidence in the rest of the country was far from negligible with detected strains that are closely related to strains isolated in Bangui. This suggests that the circulation of HEV in the CAR was highly dynamic, and both urban and rural areas had poor quality water sources that spread these pathogens.

Results from the phylogenetic analysis are consistent with previous findings regarding the subtypes circulating in the CAR and the neighboring countries, and with waterborne transmission usually associated with HEV genotypes 1 and $2[9,11]$. The high number of cases observed in Bangui in 2008-2009 following heavy rains suggests that large water sources could have been contaminated with fecal matters. Isolated cases could be due to contamination of limited water sources. Chains of asymptomatic infections of young children with adult relatives already immune might explain recurrent outbreaks. Prolonged viral excretion may also account for recurrent outbreaks.

However, our study had several limitations. Our results might highly underestimate incidence of HEV 
infections, as asymptomatic infections were not captured. In addition, not all samples were tested for HEV, nor were all samples that were tested for IgM also tested for viral RNA because of insufficient volume of some samples. In addition, 72 samples were tested by RT-PCR only because of shortage of the HEV IgM ELISA kit in the laboratory at the time of the testing, but with a likely limited impact on the study outcome given the low number of samples. It is also possible that the YF surveillance nationwide coverage was incomplete.

\section{Conclusions}

This study provides further evidences that HEV can be a leading cause of febrile jaundice cases in a Sub-Saharan country, particularly in the adults during the rainy season or following flood. These data also highlight the urgency of generating additional data to support the use of recently marketed HEV vaccine to mitigate or prevent outbreaks of hepatitis $\mathrm{E}$ and its consequences in high risk groups $[29,30]$. Finally, our study also provides an example of how to use YF national surveillance program data to investigate another disease with a significant impact on populations.

\section{Supplementary information}

Supplementary information accompanies this paper at https://doi.org/10. 1186/s12879-020-04961-4.

Additional file 1: Table S1. Number of positive samples for HEV by year of sampling and by test.

Additional file $\mathbf{2}$ : Table S2. Distribution of HEV cases by age groups and by test.

\section{Abbreviations}

CAR: Central African Republic; HEV: Hepatitis E virus; IgM: Immunoglobulin M; RNA: Ribonucleic acid; RT-PCR: Reverse transcriptase - polymerase chain reaction; YF: Yellow fever; WHO: World Health Organization

\section{Acknowledgements}

We gratefully thank all the healthcare workers who were involved in the YF surveillance. We also express our sincere thanks to the staff of the Meteorology Unit of Bangui airport for kindly providing the monthly rainfall data.

\section{Authors' contributions}

Conceived and designed the experiments: EN MK NPK. Performed the experiments: GLLN AB XK BS. Analyzed the data: VT JB NPK. Contributed reagents/materials/analysis tools: VT JB EN NPK. Wrote the paper: VT JB NPK. All authors have read and approved the manuscript.

\section{Funding}

This work was supported by the French Ministry of Research and Higher Education through a core grant to the Institut Pasteur in Bangui. The funders had no role in study design, data analysis, or preparation of the manuscript.

\section{Availability of data and materials}

The sequences generated in this study are available in GenBank under accession numbers KF734739 - KF734762. Data of the phylogenetic analysis are available at TreeBase with accession number S25902. The de-identified clinical dataset generated and analyzed during this study is available upon request from the corresponding author.

\section{Ethics approval and consent to participate}

The research was approved by the Ethics and Scientific Committee of the Faculty of Health Sciences, University of Bangui, Central African Republic (decision number 13/UB/FACSS/CSCVPER/18) and conducted within the guidelines of the declaration of Helsinki. Due to the retrospective nature of the study, written informed consent were not obtained from patients. All data were de-identified prior to analysis.

\section{Consent for publication}

Not applicable.

\section{Competing interests}

Vianney Tricou is currently employed by Takeda Pharmaceuticals International AG, Zurich, Switzerland. All other authors have declared that no competing interests exist.

\section{Author details}

${ }^{1}$ Laboratoire des Arbovirus, Institut Pasteur de Bangui, Bangui, Central African Republic BP 923. ${ }^{2}$ Institut Pasteur, Bangui, Central African Republic. ${ }^{3}$ Laboratoire des Hépatites Virales, Institut Pasteur, Bangui, Central African Republic. “Laboratoire d'Analyses Médicales, Institut Pasteur, Bangui, Central African Republic. Institut Pasteur, Bangui, Central African Republic, and Institut Pasteur, Cayenne, French Guiana.

Received: 31 August 2019 Accepted: 11 March 2020

Published online: 03 April 2020

\section{References}

1. Azman AS, Ciglenecki I, Wamala JF, Lynch J, Aggarwal R, Rahman M, et al. Hepatitis E should be considered a neglected tropical disease. PLoS Negl Trop Dis. 2019;13(7):e0007453.

2. Carratalà A, Joost S. Population density and water balance influence the global occurrence of hepatitis E epidemics. Sci Rep. 2019;9(1):10042.

3. Hoofnagle JH, Nelson KE, Purcell RH. Hepatitis E. N Engl J Med. 2012;367(13): $1237-44$.

4. Khuroo MS, Teli MR, Skidmore S, Sofi MA, Khuroo MI. Incidence and severity of viral hepatitis in pregnancy. Am J Med. 1981;70(2):252-5.

5. Boccia D, Guthmann JP, Klovstad H, Hamid N, Tatay M, Ciglenecki I, et al. High mortality associated with an outbreak of hepatitis $\mathrm{E}$ among displaced persons in Darfur, Sudan. Clin Infect Dis. 2006;42(12):1679-84.

6. World Health Organization. Hepatitis E. fact sheet N²80. Geneva: World Health Organization; 2017

7. UNDP. Human Development Report 2016. New York: United Nations Development Programme; 2016.

8. Pawlotsky JM, Bélec L, Grésenguet G, Deforges L, Bouvier M, Duval J, et al. High prevalence of hepatitis $B, C$, and $E$ markers in young sexually active adults from the Central African Republic. J Med Virol. 1995;46(3):269-72.

9. Escribà JM, Nakoune E, Recio C, Massamba PM, Matsika-Claquin MD, Goumba C, et al. Hepatitis E, Central African Republic. Emerg Infect Dis. 2008:14(4):681-3.

10. Goumba Al, Konamna X, Komas NP. Clinical and epidemiological aspects of a hepatitis E outbreak in Bangui, Central African Republic. BMC Infect Dis. 2011;11:93.

11. Bouscaillou J, Komas N, Tricou V, Nakouné E, Sélékon B, Fontanet A, et al. Imported hepatitis e virus, Central African Republic, 2011. Emerg Infect Dis. 2013;19(2):335-7.

12. World Health Organization. WHO-recommended standards for surveillance of selected vaccine-preventable diseases. Geneva: World Health Organization; 2008

13. Rachas A, Nakouné E, Bouscaillou J, Paireau J, Selekon B, Senekian D, et al. Timeliness of yellow fever surveillance, Central African Republic. Emerg Infect Dis. 2014;20(6):1004-8.

14. Norder $\mathrm{H}$, Karlsson M, Mellgren A, Konar J, Sandberg E, Lasson A, et al. Diagnostic performance of five assays for anti-hepatitis $E$ virus $\lg G$ and IgM in a large cohort study. J Clin Microbiol. 2016;54(3):549-55.

15. Pas SD, Streefkerk RH, Pronk M, de Man RA, Beersma MF, Osterhaus AD, et al. Diagnostic performance of selected commercial HEV IgM and IgG ELISAs for immunocompromised and immunocompetent patients. J Clin Virol. 2013;58(4):629-34.

16. Enouf V, Dos Reis G, Guthmann JP, Guerin PJ, Caron M, Marechal V, et al. Validation of single real-time TaqMan PCR assay for the detection and 
quantitation of four major genotypes of hepatitis $E$ virus in clinical specimens. J Med Virol. 2006;78(8):1076-82.

17. Huang FF, Haqshenas G, Guenette DK, Halbur PG, Schommer SK, Pierson FW, et al. Detection by reverse transcription-PCR and genetic characterization of field isolates of swine hepatitis $E$ virus from pigs in different geographic regions of the United States. J Clin Microbiol. 2002; 40(4):1326-32.

18. Smith DB, Simmonds $P$, Izopet J, Oliveira-Filho EF, Ulrich RG, Johne R, et al. Proposed reference sequences for hepatitis E virus subtypes. J Gen Virol. 2016;97(3):537-42.

19. Guindon S, Dufayard JF, Lefort V, Anisimova M, Hordijk W, Gascuel O. New algorithms and methods to estimate maximum-likelihood phylogenies: assessing the performance of PhyML 3.0. Syst Biol. 2010;59(3):307-21.

20. Lefort V, Longueville JE, Gascuel O. SMS: smart model selection in PhyML. Mol Biol Evol. 2017:34:2422-4.

21. General Directorate of Statistics, Economic and Social Studies, Central African Republic. Population, 2003, Central African Republic. 2003.

22. Akanbi OA, Harms D, Wang B, Opaleye OO, Adesina O, Osundare FA, et al. Complete genome sequence of a hepatitis $E$ virus genotype 1e strain from an outbreak in Nigeria, 2017. Microbiol Resour Announc. 2019;8(1):e01378-18.

23. Wang B, Akanbi OA, Harms D, Adesina O, Osundare FA, Naidoo D, et al. A new hepatitis $E$ virus genotype 2 strain identified from an outbreak in Nigeria, 2017. Virol J. 2018;15(1):163.

24. Lhomme S, Abravanel F, Dubois M, Chapuy-Regaud S, Sandres-Saune K, Mansuy JM, et al. Temporal evolution of the distribution of hepatitis E virus genotypes in southwestern France. Infect Genet Evol. 2015;35:50-5.

25. Dimeglio C, Kania D, Mantono JM, Kagoné T, Zida S, Tassembedo S, et al. Hepatitis E virus infections among patients with acute febrile jaundice in Burkina Faso. Viruses. 2019;11(6):554

26. World Health Organization. Waterborne outbreaks of hepatitis E: recognition, investigation and control - technical report. Geneva: World Health Organization; 2014.

27. Caron M, Kazanji M. Hepatitis E virus is highly prevalent among pregnant women in Gabon, Central Africa, with different patterns between rural and urban areas. Virol J. 2008:14:158.

28. Tucker TJ, Kirsch RE, Louw SJ, Isaacs S, Kannemeyer J, Robson SC. Hepatitis E in South Africa: evidence for sporadic spread and increased seroprevalence in rural areas. J Med Virol. 1996;14:117-9.

29. World Health Organization. Hepatitis E vaccine: WHO position paper, may 2015. Wkly Epidemiol Rec. 2015;90:185-200.

30. Cooper BS, White L, Siddiqui R. Reactive and pre-emptive vaccination strategies to control hepatitis $E$ infection in emergency and refugee settings: A modelling study. PLoS Negl Trop Dis. 2018;12(9):e0006807.

\section{Publisher's Note}

Springer Nature remains neutral with regard to jurisdictional claims in published maps and institutional affiliations.

Ready to submit your research? Choose BMC and benefit from:

- fast, convenient online submission

- thorough peer review by experienced researchers in your field

- rapid publication on acceptance

- support for research data, including large and complex data types

- gold Open Access which fosters wider collaboration and increased citations

- maximum visibility for your research: over $100 \mathrm{M}$ website views per year

At $\mathrm{BMC}$, research is always in progress.

Learn more biomedcentral.com/submissions 